\title{
Liderança e empreendedorismo no conselho de administração das cooperativas
}

O Conselho de Administração é o órgão da alta administração da cooperativa, responsável pela execução do planejamento estratégico, composto por membro eleitos pelo colegiado. Esse trabalho teve como objetivo estudar as características empreendedoras e de liderança presentes nos membros do conselheiro de administração nas cooperativas. Por meio da pesquisa bibliográfica, buscou-se descrever o perfil empreendedor, principalmente daqueles que atuam no coletivo, assim como as características presentes nas lideranças. Os resultados inferem que para o cargo de conselheiro de administração são necessários: conhecimentos técnicos, conhecimentos gerenciais, habilidades interpessoais e experiências prévias. O sucesso da organização está ligado à capacidade de seus gestores em tomarem decisões assertivas e tempestivas, sendo fundamental a formação de líderes empreendedores capazes de trabalhar com cooperação, visão sistêmica, ética, inovação e vontade de evoluir.

Palavras-chave: Empreendedorismo; Liderança; Cooperativas; Conselho de Administração.

\section{Leadership and entrepreneurship on cooperative board of directors}

The Board of Directors is the cooperative's top management body, responsible for executing the strategic planning, composed of members elected by the collegiate. This work aimed to study the entrepreneurial and leadership characteristics present in the members of the board of directors in the cooperatives. Through bibliographic research, we sought to describe the entrepreneurial profile, especially of those who work in the collective, as well as the characteristics present in the leaders. The results infer that for the position of management advisor, technical knowledge, managerial knowledge, interpersonal skills and previous experiences are necessary. The organization's success is linked to the ability of its managers to make assertive and timely decisions, and the formation of entrepreneurial leaders capable of working with cooperation, systemic vision, ethics, innovation and the will to evolve is essential.

Keywords: Entrepreneurship; Leadership; Cooperatives; Board Directors.

Topic: Empreendedorismo

Reviewed anonymously in the process of blind peer.
Received: $11 / 05 / 2020$

Approved: 22/08/2020
Vando Vieira Batista dos Santos (iD

Centro Universitário Leonardo da Vinci, Brasil

http://lattes.cnpq.br/0929198787654434

http://orcid.org/0000-0001-5433-9331

vandodmj@gmail.com

Flávia Monaco Vieira (iD

Universidade La Salle, Brasil

http://lattes.cnpq.br/3124206982085534

http://orcid.org/0000-0003-0851-6506

flavia.201910304@unilasalle.edu.br
Referencing this:

SANTOS, V. B.; VIEIRA, F. M.. Liderança e empreendedorismo no conselho de administração das cooperativas. Management Journal, v.2, n.2, p.1-9, 2020. DOI: http://doi.org/10.6008/CBPC2674$\underline{6417.2020 .002 .0001}$ 


\section{INTRODUÇÃO}

A sociedade se transforma pelas ideias inovadoras e pelas pessoas que tem coragem de empreender. Por meio do empreendedorismo, a organização desenvolve seu potencial, se fortalece e transforma obstáculos em oportunidades. No cooperativismo pode-se encontrar o empreendedor coletivo, que se destaca pela cooperação e comprometimento.

Neste cenário de cooperação, encontra-se a necessidade de desenvolver a liderança, ou seja, pessoas com perfil de líder que trabalhem em prol da melhoria contínua, capazes de motivar os demais indivíduos e gerar ganhos mútuos. O Conselho de Administração é órgão responsável pela administração da cooperativa, sendo essencial aos conselheiros desenvolver as características empreendedoras, contribuindo para o crescimento da cooperativa, através de sua capacidade de ir além, buscar soluções coletivas e resultados positivos em prol de todos.

O objetivo deste trabalho é estudar as características empreendedoras e de liderança dos membros dos conselheiros de administração nas cooperativas. Para contemplar esse objetivo, serão descritas as características de um empreendedor, especialmente daqueles que atuam nas cooperativas (empreendedores coletivos), as características presentes nas lideranças e as atividades do conselho de administração da cooperativa.

A importância desta pesquisa refere-se ao fato que organizações bem-sucedidas são aquelas que possuem uma boa liderança, compostas por empreendedores que sabem cooperar. Em termos de contribuição, é importante por destacar a necessidade da formação de líderes.

\section{METODOLOGIA}

O desenvolvimento do estudo foi elaborado através de pesquisa bibliográfica, estruturado em três subtópicos que abordarão sobre empreendedorismo e o perfil empreendedor, empreendedor coletivo e os líderes nas cooperativas, e por fim, sobre o conselho de administração das cooperativas.

\section{DISCUSSÃO TERÓRICA}

\section{Empreendedorismo e o perfil empreendedor}

O empreendedorismo proporciona um elevado grau de autorrealização pessoal, por ser a exteriorização do sonho e por receber o empreendedor com todas as suas características. A atividade empreendedora une o trabalho e a satisfação pessoal, favorecendo a concretização dos objetivos traçados.

Empreendedor é o indivíduo que possui uma atitude de inquietação, ousadia e proatividade na relação com o mundo. Essa postura, condicionada por características pessoais, pela cultura e pelo ambiente, favorece a interferência criativa e realizadora, no meio, resultando em ganhos econômicos e sociais. (SEBRAE, 2006)

Ser empreendedor significa ter, acima de tudo, a necessidade de realizar coisas novas, pôr em prática ideias próprias, motivando os outros a colaborarem com o seu melhor para a realização dos seus objetivos. O empreendedor destaca-se porque, independentemente de suas atividades, ele faz com que as coisas 
aconteçam, tendo uma visão futura de todo empreendimento.

Segundo Dantas et al. (2011), "o que diferencia o empreendedor do empresário são as motivações para criar algo novo. O empresário visa essencialmente o lucro, já o empreendedor encara o lucro como consequência". As características predominantes da personalidade do empreendedor, segundo Bernardi (2012), são: senso de oportunidade; dominância; agressividade e energia para realizar; autoconfiança; otimismo; dinamismo; independência; persistência; flexibilidade e resistência e frustrações; criatividade; propensão ao risco; liderança carismática; habilidade de equilibrar "sonho" e realização; e habilidade de relacionamento.

Uma pessoa com perfil empreendedor deseja "deixar sua marca", buscando fazer as coisas acontecerem. "São pessoas que acreditam que é preciso lutar por aquilo que querem e que são responsáveis pelo seu próprio sucesso" (SEBRAE, 2006). O empreendedor imagina e define o contexto organizacional necessário para alcançar o fim desejado, com visão a médio e longo prazo. Criar visões significa, essencialmente, identificar e dar sentido ou direção às atividades subsequentes.

"Os empreendedores aprendem a conhecer as atividades necessárias para o sucesso das organizações. Eles detectam possibilidades de negócios, imaginam, definem, e selecionam um espaço de mercado que pretendem ocupar e então, criam o tipo de organização necessário para fazê-lo" (FILION, 1999). Algumas das características marcantes do empreendedor para alcançar o sucesso, segundo Sebrae (2006) são: garra, determinação, disposição de aprender e vontade de vencer. Algumas características são básicas no comportamento empreendedor e, portanto, podem ser desenvolvidas.

Neste sentido, Drucker (1987) afirma que "o empreendedorismo é um comportamento, e não uma personalidade. Qualquer indivíduo que tenha à frente uma decisão a tomar pode aprender a ser um empreendedor e se comportar empreendedoramente". Para atingir o melhor nas instituições torna-se cada vez mais necessário o desenvolvimento de um perfil empreendedor, procurando adquirir algumas características empreendedoras que direcione seu comportamento para alcançar seus objetivos.

\section{Empreendedorismo coletivo e líderes nas cooperativas}

De acordo com a Organização das Cooperativas Brasileiras - OCB (2017), "mais que um modelo de negócios, o cooperativismo é uma filosofia de vida que busca transformar o mundo em um lugar mais justo, feliz, equilibrado e com melhores oportunidades para todos". Nas cooperativas, os associados participam da gestão e usufruem de seus produtos e serviços. Todos associados possuem o mesmo poder de voto, independentemente da sua cota de participação no capital social da cooperativa; os direitos e deveres de todos são iguais e a adesão é livre e voluntária.

O cooperativismo pode ser o ponto de partida para o avanço de muitos projetos e produtos, agregando ideias, recursos e mais conhecimento. O fator principal de um projeto de cooperativismo é a competitividade, a união de pequenas forças que transforma tudo em uma força enorme. (NUNES, 2017)

As cooperativas devem ser formadas por empreendedores que possuam capacidades sociais adquiridas através do aprendizado tácito e nos saberes práticos locais. De acordo com Vale (2004), "o 
empreendedor coletivo é um agente externo capaz de usufruir de novas oportunidades, gerando e explorando as sinergias provenientes da ação coletiva".

O empreendedorismo coletivo proporciona vantagens como redução de custos de transação e de produção; redução dos impactos de informações assimétricas e seleção adversa; e dos graus de oportunismo e incerteza inerentes ao funcionamento do mercado em economias capitalistas. (SANTOS, 2014)

O empreendedor coletivo é um agente que percebe o valor econômico que surge da cooperação. Conforme Vale (2004), “este agente empreendedor - novo, fundamental e ainda hoje não mapeado adequadamente- não está claramente desenhado nem mesmo nas recentes formulações correntes em torno da criação de uma taxonomia de tipos de empreendedores".

O empreendedorismo coletivo requer confiança e cooperação, aumentando a lealdade e comprometimento. Assim como o empreendedorismo, a liderança é uma característica essencial presente nas cooperativas. Conforme SEBRAE (2018) "não existe cooperação sem liderança. Um líder pode ser a diferença para o sucesso de um empreendimento coletivo".

As características essenciais dos líderes eficazes abrangem inteligência básica, valores claros e sólidos, níveis elevados de energia pessoal, capacidade e vontade de crescer constantemente, visão, curiosidade contagiosa, boa memória e capacidade de fazer com que os seguidores se sintam bem consigo mesmos. (MERIGHI et al., 2013)

O líder tem diversas características, sendo capaz de comprometer as pessoas com a ação e converter os seguidores também em líderes, transformando-os em agentes de mudança. O Sebrae (2018) define o líder empreendedor como aquele capaz de desenvolver os talentos e as competências do grupo na busca dos objetivos comuns que se pretendem alcançar.

Para Merighi et al. (2013), “em seu papel mais importante hoje, o líder eficaz é aquele capaz de criar condições para o florescimento da liderança em outros, identificando e cultivando líderes potenciais em todos os níveis". Em alinhamento, Medeiros (2013) afirma, "liderança hoje é ter a visão, a humildade e a habilidade, de formar novos líderes, através de critérios técnicos, éticos e profissionais".

A cooperativa necessita de lideranças com o perfil adequado, com indivíduos que expandem suas capacidades de entender complexidades, esclarecer visões e aperfeiçoar modelos mentais compartilhados. Para Merighi et al. (2013), "um líder focado na realização de tarefas pode obter péssimos resultados, enquanto um líder focado no relacionamento e manutenção do grupo pode obter seus objetivos com alto nível de satisfação de ambas as partes". Os líderes nas cooperativas devem estar alinhados aos valores do cooperativismo, possuir o conhecimento técnico sobre a gestão das cooperativas e agir sempre de forma empreendedora dentro da organização.

Alguns conhecimentos necessários aos líderes, segundo Merighi et al. (2013), são: Visão global: conhecer a cultura da instituição, seu posicionamento no mercado e o que fazer para a melhoria contínua; Visão sistêmica: saber que todos os setores da organização são importantes, valorizando cada serviço realizado; Diagnosticar contextos: saber o que a equipe precisa, até mesmo de capacitação para o desenvolvimento ou pré-requisitos básicos para exercer funções; Planejar: estabelecer objetivos e gerenciar a organização com foco a atingir os resultados. Observar como esses resultados foram atingidos e se existe 
necessidade de revê-los; Agente de mudança: o líder deve provocar mudanças. Deve estar atento e propor inovações através de uma leitura de necessidades (equipe, cliente e mercado); Prever e não apenas reagir: a liderança deve tomar atitudes preventivas, alavancar obstáculos e estabelecer alternativas; Buscar gestão participativa: isto gera comprometimento. Nesse tipo de gestão, o líder deve perguntar sempre a forma de ação, para que não joguem sobre ele simplesmente ideias soltas e sem um raciocínio de praticidade; Ter habilidade para correr riscos: enfrentar os desafios. Cada desafio superado é acompanhado de crescimento e ampliação de seu repertório de respostas até às soluções e problemas. O líder cresce na medida em que se expõe; Saber buscar informações: tudo modifica. O líder deve ler, investigar e conversar com outros profissionais de sua área. Ampliar sua fonte de informação e direcionar o que vai fazer com elas para ele não ficar apenas no grau informativo e poder passar para o grau de conhecimento, ou seja, a liderança deve adaptar as informações à sua realidade e colocá-las em prática. Ter uma boa rede de contatos. Informação é poder: quanto mais sabe, mais pode conhecer e ser respeitado; Ser eficiente: é ser cumpridor do dever e da rotina de trabalho, verificar se a metodologia é adequada; é acompanhar todo o processo e fazer com que este funcione. Ter em mente que sua atividade principal é orientar a forma correta de trabalho. Ser eficiente não basta ao papel de líder. É fundamental que a liderança esteja à frente de seu tempo, pois isso enriquecerá as funções; Ter uma logística: saber de onde vem e para onde vai seu trabalho e a consequência de sua boa elaboração.

Desta forma, o líder precisa assumir sua função na gestão do coletivo, baseando-se nos princípios da cooperação. Ele articula as forças em torno dos objetivos comuns do grupo, associando recursos e integrando competências para que, todos juntos, unindo forças, possam fazer mais e melhor com menos. (SEBRAE, 2018). Assim como o empreendedorismo, a liderança pode ser aprendida. Para Merighi et al. (2013), "a capacidade para liderar não é hereditária, mas sim se vai aprendendo com as experiências ao longo da vida, e o grau de aprendizagem de cada uma delas pode ditar o sucesso do Líder em questão".

Reisdorfer (2014) destaca alguns problemas que o sistema cooperativo enfrenta atualmente, entre eles: Em torno de $90 \%$ das cooperativas tem problemas de ordem cultural, ou seja, pouco ou deficiente conhecimento do que é o cooperativismo e como praticá-lo nos processos de empreendimento econômico; Em 70\% identificam-se problemas de profissionais que não possuem perfil e qualificação para gerenciar um empreendimento como o negócio cooperativo, faltando treinamento adequado, capacitação, uso de ferramentas ou falta de tecnologia adequada para bem gerir; Em torno de 50\% (cinquenta por cento) das cooperativas existem problemas financeiros relevantes, decorrentes da falta ou fragilidade no planejamento.

Desta forma, "preparar um novo perfil de formação de gestores, com uma visão mais reflexiva sobre o sistema, e com habilidades e competências para solucionar os problemas do dia a dia, planejando e operando o funcionamento da organização, pode ser uma forma de reverter os índices de fracasso do setor cooperativo". A formação de líderes com habilidades e características singulares pode contribuir para a gestão das cooperativas. De acordo com Medeiros (2013), "a liderança moderna possui clareza estratégica, fazendo com que a 'Missão, Visão, Valores e Objetivos' sejam assimilados e praticados por todos os colaboradores de forma consciente, criando assim um alinhamento, um sentimento e atitude de 
cooperação".

A gestão dos novos líderes deve estar voltada para os princípios de transparência, eficiência, eficácia, equidade, conformidade às leis e responsabilidade corporativa. Desta forma, Reisdorfer (2014, p. 104), destaca que as cooperativas precisam de líderes idôneos, sem agendas ocultas, com uma visão holística da causa cooperativa e, principalmente, que tenham capacidade de transformar, melhorando o modelo da governança, com maior transparência e assertividade nas decisões.

\section{Conselho de administração nas cooperativas}

A cooperativa é gerida pelos próprios associados, sendo o conselho de administração o órgão gestor e superior que executa o planejamento aprovado pela assembleia geral. As suas funções estão definidas pela estrutura organizacional, conforme o estatuto social da cooperativa. O conselho de administração das cooperativas é composto exclusivamente de associados eleitos pela Assembleia Geral, com mandato nunca superior a 4 (quatro) anos, sendo obrigatória a renovação de, no mínimo, 1/3 (um terço) dos conselheiros. (Art. 47, Lei 5.764/71). O prazo de mandato envolve a capacidade de contribuição efetiva do conselheiro para o bom desempenho do colegiado em determinado período de tempo.

São inelegíveis, além das pessoas impedidas por lei, os condenados à pena que vede, ainda que temporariamente, o acesso a cargos públicos; ou por crime falimentar, de prevaricação, peita ou suborno, concussão, peculato, ou contra a economia popular, a fé pública ou a propriedade. (Art. 51, Lei 5.764/71)

De acordo com IBGC (2016) "na qualidade de administradores, todos os conselheiros, uma vez eleitos, possuem deveres fiduciários para com a companhia, devendo agir no melhor interesse da organização".

A missão dos membros dos conselhos de administração envolve várias atitudes. Segundo Pontes et al. (2009) as ações dos Conselheiros requerem: Ponderação e Equilíbrio: Quando dos tratamentos dos problemas surgidos na cooperativa, dos mais simples aos mais complexos, quer quando do entendimento entre os próprios conselheiros e conselhos, quer no relacionamento com associados, gerentes, contador e demais colaboradores; Descrição: Evitando que os fatos administrados e/ou fiscalizados gerem falsos alarmes; Minuciosidade: Que levará o exame de todos os pormenores que possam interessar ao esclarecimento dos fatos, junto aos associados e Assembleia Geral; Prudência: Evitando que se formulem acusações infundadas, sem a devida comprovação; Sacrifício: Porque o associado, desde que aceitou o cargo tem que dispor de tempo capacidade de dedicação que implica, muitas vezes, em renúncia às suas próprias atividades, procurando cumprir o seu mandato de maneira correta e responsável.

O IBGC (2016) realizou uma pesquisa do perfil dos conselhos de administração, tendo como amostra 339 companhias listadas nos segmentos diferenciados de governança corporativa (Novo Mercado, Nível 2 e Nível 1) e no segmento Tradicional, sendo a amostra de 2.244 conselheiros. $O$ quadro 1 apresenta alguns dos resultados dessa pesquisa:

No Relatório de Sustentabilidade 2017, o Sicredi (2017) destaca alguns pontos importantes quanto às lideranças da cooperativa de crédito e sua estratégia de gestão: Inclusão: ainda é um desafio o 
desenvolvimento da liderança das mulheres, pois o Sistema encontrou barreiras na implantação de ações que as coloquem em posições de liderança. Para engajar e preparar líderes associadas, o Sistema tem desenvolvido os Comitês Mulher, a fim de que futuramente elas possam assumir posições mais estratégicas nas Cooperativas; Faixa etária dos associados: envolve a inclusão do público jovem. Para atrair este público à causa cooperativa são necessários produtos e serviços que atendam às suas necessidades, além de criar movimentos que despertem o interesse desse público para o cooperativismo; Educação: investir em educação é contribuir para o desenvolvimento de uma sociedade mais justa, solidária e cidadã. Visando também qualificar a participação dos associados como donos do negócio, fortalecendo assim sua relação com sua cooperativa de crédito.

Quadro 1: Resultados da pesquisa do perfil dos conselheiros de administração.

\begin{tabular}{|l|l|}
\hline Diversidade & Resultados \\
\hline Gênero & A participação das mulheres é de 7,9\% do total de assentos efetivos disponíveis. \\
\hline Profissão & $\begin{array}{l}\text { O conselheiro típico possui formação em engenharia (27,6\%), administração (21,4\%), } \\
\text { economia (15,6\%) ou direito (13,3\%). }\end{array}$ \\
\hline Faixa etária & Mais de 50\% dos conselheiros possuem idade entre 50 e 69 anos. \\
\hline $\begin{array}{l}\text { Experiência Profissional Prévia como } \\
\text { Executivo Sênior }\end{array}$ & $\begin{array}{l}\text { Aproximadamente 75\% dos membros efetivos do conselho informaram possuir } \\
\text { experiência prévia como conselheiro(a). }\end{array}$ \\
\hline
\end{tabular}

Fonte: Adaptado de IBGC (2016).

Em 2016, o Conselho Monetário Nacional publicou a Resolução $n^{\circ} 4.538$ que dispôs sobre a política de sucessão de administradores das instituições financeiras e demais instituições autorizadas a funcionar pelo Banco Central do Brasil, englobando as cooperativas de crédito. A normativa obrigou a organização a pensar sobre o perfil dos líderes que deverão ocupar os cargos da alta administração e estruturar com base em regras a identificação, a avaliação, o treinamento e a seleção dos candidatos aos cargos. No mínimo, devem ser considerados os seguintes aspectos:

I - Condições para o exercício do cargo exigidas pela legislação e pela regulamentação em vigor;

II - Capacidade técnica;

III - capacidade gerencial;

IV - Habilidades interpessoais;

V - Conhecimento da legislação e da regulamentação relativas à responsabilização de qualquer natureza por sua atuação; e

VI - Experiência. (Art. 3, Resolução do CMN no 4.538/2016)

Conforme Pontes et al. (2009) o perfil ideal dos conselheiros são: Disponibilidade de tempo: Aos cargos de conselheiros de administração, o tempo não é um requisito de grande importância, pois sua necessidade é apenas nos dias de reunião; Noções Básicas sobre o funcionamento de uma cooperativa e sobre cooperativismo: Os conselheiros devem conhecer os aspectos que distinguem uma cooperativa de outros tipos de empresa. Devem ter consciência e acreditar na validade teórica e prática do cooperativismo e da cooperação; Noções e/ou experiências na área de administração, economia e contabilidade: É importante que os conselheiros de administração possam se familiarizar rapidamente com os procedimentos simples da administração e fiscalização. Saibam os objetivos de um planejamento, de um balancete, de um relatório de gestão; Experiência em Cooperativas: Esta condição está relacionada, principalmente, à 
capacidade de liderança dos conselheiros; a habilidade de se mover nas questões políticas da sociedade; de prever as implicações políticas de medidas administrativas junto aos associados; de administrar, com eficiência, os problemas surgidos, em benefício dos associados e da cooperativa.

\title{
CONCLUSÕES
}

Os associados das cooperativas são empreendedores natos, que carregam um gama de características únicas, tais como: cooperação, persistência, inovação, visão de futuro e assunção de riscos, podendo muitas vezes desenvolver a liderança.

No cooperativismo, os associados dividem os mesmos valores e buscam os mesmos resultados, assim precisam estar alinhados, por meio da cooperação, para prosperar. Verifica-se que através do empreendedorismo e da liderança a instituição pode avançar, garantindo sua continuidade e melhor desempenho frente às situações a serem enfrentadas. Sendo assim necessária a formação de líderes que conheçam o sistema, encontre soluções e profissionalizem a gestão da cooperativa.

\begin{abstract}
Uma equipe de alto desempenho tem que ter pessoas preparadas para orientar, coordenar e acompanhar o esforço de todos para os mesmos objetivos. O sucesso ou fracasso da empresa cooperativa depende de vários atores na organização, como o dirigente, (que é o líder escolhido democraticamente pelos associados), o seu conselho administrativo e seus funcionários, porque eles são, diretamente, os responsáveis pela condução, tomada de decisão e pela implementação de projetos. (REISDORFER, 2014)
\end{abstract}

Os líderes das cooperativas devem ter habilidades múltiplas para geri-la com eficiência, entendendo as questões culturais, os valores do cooperativismo, políticas públicas, economia, temas ligados ao meio ambiente, educação e social. Através de uma gestão voltada para o desenvolvimento social e econômico, os líderes se tornam indispensáveis para o sucesso da cooperativa.

O Conselho de Administração, como órgão gestor superior, responsável por executar o planejamento estratégico da cooperativa, precisa possuir capacidade técnica, capacidade gerencial, habilidade interpessoal, conhecimento legal e experiência. O conselheiro de administração possui um papel de liderança nas cooperativas, fomentando a participação, ética, e agindo com profissionalismo, além de características empreendedoras, que garantam a continuidade da instituição por meio da gestão eficaz e inovadora.

\section{REFERÊNCIAS}

BERNARDI, L. A.. Manual de Empreendedorismo e Gestão: Fundamentos, Estratégias e Dinâmicas. 2 ed. São Paulo: Atlas, 2012.

DANTAS, M. Z.; OLIVEIRA, M. M. V.; COSTA, J. S.; SOUZA, S. M.; VIEIRA, J.. O perfil empreendedor das Associadas da Cooperativa de Artesanato do Sudoeste da Bahia CRIAR E RECRIAR. Núcleo de Pesquisa Aplicada e Incubação de Empreendimentos Solidários da UESB, 2011.

IBGC. Instituto Brasileiro de Governança Corporativa. Perfil dos conselhos de administração. São Paulo: IBGC, 2016.

MEDEIROS, M. C.. Liderança cooperativa. Portal dos Administradores, 2017.
MERIGHI, C. C.; LIMA, T. B.; ALBUQUERQUE, F. B.; ORNEDO, R.. Estudos do comportamento da liderança na Cooperativa de Crédito Rural Centro Norte do Mato Grosso do Sul, unidade Chapadão do Sul, como fator de desenvolvimento local. Interações (Campo Grande), v.14, n.2, p.165-176, 2013. DOI: https://doi.org/10.1590/S151870122013000200003

NUNES, S.. Cooperativismo e Empreendedorismo. Sabrina Nunes, 2017.

PONTES, H. S.; PINTO, D. M.. Formação de Conselheiros Fiscais de Cooperativas. Santarém: Serviço Florestal Brasileiro, 2009. 
SANTOS, J. A. G.. Estrutura de Governança. Cooperativismo e Empreendedorismo: $O$ caso da cadeia produtiva do café em Barra do Choça - Bahia. In: ENCONTRO DE ESTUDOS EM EMPREENDEDORISMO E GESTÃO DE PEQUENAS EMPRESAS, 8. Anais. Goiânia: EGEPE, 2014.

SEBRAE. Serviço Brasileiro de Apoio às Micro e Pequenas Empresas. A importância da liderança no trabalho coletivo. SEBRAE, 2018.
SICREDI. Sistema de Crédito Cooperativo. Relatório de Sustentabilidade 2017. SICREDI, 2018.

VALE, G. M. V.. Empreendedores coletivos em redes organizacionais: novos agentes gerando um padrão diferenciado de competitividade. In: ENCONTRO NACIONAL DOS PROGRAMAS DE PÓS-GRADUAÇÃO EM ADMINISTRAÇÃO, Anais. Curitiba: ANPAD, 2004.

A CBPC - Companhia Brasileira de Produção Científica (CNPJ: 11.221.422/0001-03) detém os direitos materiais desta publicação. Os direitos referem-se à publicação do trabalho em qualquer parte do mundo, incluindo os direitos às renovações, expansões e disseminações da contribuição, bem como outros direitos subsidiários. Todos os trabalhos publicados eletronicamente poderão posteriormente ser publicados em coletâneas impressas sob coordenação da Sapientiae Publishing, da Companhia Brasileira de Produção Científica e seus parceiros autorizados. Os (as) autores (as) preservam os direitos autorais, mas não têm permissão para a publicação da contribuição em outro meio, impresso ou digital, em português ou em tradução. 